\title{
On some morphological and ultrastructural features of the insemination system in five species of the genus Brevipalpus (Acari: Tenuipalpidae)
}

\author{
Antonella Di Palma ${ }^{1}$ (D) - Aline D. Tassi ${ }^{2}$ - Elliot W. Kitajima ${ }^{2}$
}

Received: 19 May 2020 / Accepted: 24 July 2020 / Published online: 3 August 2020

(c) The Author(s) 2020

\begin{abstract}
The genus Brevipalpus (Tenuipalpidae) includes 291 described species commonly found in the tropical and subtropical regions. Morphological characters considered in the taxonomy of Brevipalpus species are difficult to discern, which often leads to erroneous identifications and the presence of cryptic species within species is suspected. New morphological characters are now considered relevant for identification of Brevipalpus species; among them, the morphology of the seminal receptacle (spermatheca) of the female insemination system. This feature has not been considered relevant until now; thus, there is little information about the insemination system in the available species descriptions. Hence, in the present study, ultrastructural details are provided for the insemination system in five species of Brevipalpus, representing different morphological groups. The seminal receptacle (spermatheca) and the insemination duct are illustrated using light, transmission and scanning electron microscopy. The spermatheca proved to have specific morphological features that can be useful for taxonomic purposes. On the other hand, its appearance within a population might be variable in a way that needs to be ascertained and evaluated.
\end{abstract}

Keywords Spermatheca $\cdot$ Taxonomy $\cdot$ Identification $\cdot$ Electron microscopy

\section{Introduction}

The genus Brevipalpus belongs to the family Tenuipalpidae (Acari: Prostigmata) and includes 291 described species (Mesa et al. 2009; Castro et al. 2019) commonly found in the tropical and subtropical regions. This genus has great economic importance within the family, because some species were found to transmit phytopathogenic viruses such as Citrus leprosis virus $C$ (CiLV-C), Coffee ringspot virus (CoRSV), Passion fruit green spot virus (PfGSV) and Orchid fleck virus (OFV) (Kitajima et al. 2014). In particular, three species have been regarded as

Antonella Di Palma

antonella.dipalma@unifg.it

1 Department of the Sciences of Agriculture, Food and Environment, University of Foggia, 71100 Foggia, Italy

2 Departamento de Fitopatologia e Nematologia, Escola Superior de Agricultura Luiz de Queiroz (ESALQ), Universidade de São Paulo (USP), Piracicaba, SP 13418-900, Brazil 
plant virus vectors: Brevipalpus californicus (Banks), Brevipalpus obovatus Donnadieu and Brevipalpus phoenicis (Geijskes) (Childers et al. 2003).

Regarding species identification, several morphological characters (e.g., reticulation and details on the cuticle patterns in specific regions of the mite body) used in the taxonomy of Brevipalpus are rather difficult to discern, which often leads to erroneous or uncertain identifications. In addition, the appearance of some of these characters may be affected by the age of individuals, diet and mounting techniques (Welbourn et al. 2003). Recent papers reviewing the genus Brevipalpus, based on both morphological features (Beard et al. 2015) and molecular markers of the mitochondrial cytochrome oxidase I (COI) gene (Rodrigues et al. 2004; Groot and Breeuwer 2006; Navia et al. 2013), suggested a greater diversity of species, showing some incongruities in the morphological descriptions, when compared with molecular markers, and the possible presence of cryptic species. Therefore, a revaluation of the status of Brevipalpus species has become necessary.

In particular, new morphological characteristics are now considered relevant for the identification of Brevipalpus species; among them, the morphology of the seminal receptacle (spermatheca) of the female insemination system (Ochoa et al. 2011; Beard et al. 2015). The shape of the spermatheca has already been used for discerning mite species in Phytoseiidae (e.g., Chant and McMurtry 2007). Moreover, attempts have been made to use the morphology of this structure to separate species in some plant mites (e.g., Vacante 1983, 1984; Beard et al. 2015) and this structure morphology could also be correlated to molecular phylogeny lineages suggesting it is evolutionarily conserved in groups like Eriophyoidea (Chetverikov et al. 2015, 2020; Chetverikov and Petanović 2016).

Nevertheless, this character has not been used in the identification of Brevipalpus species. In a rather old paper (Castagnoli 1974) there is the first reference to the presence of a spermatheca in the Tenuipalpidae, including the description of this structure in eight species. Later, Baker and Tuttle (1987) described the shape of the spermatheca in some Brevipalpus species from Mexico. Yet, for most of the described Brevipalpus species, the authors did not observe this structure, sometimes ascribing this to the clearing action of the mounting medium and the age of the females (Baker and Tuttle 1987). In any case taxonomic papers with species descriptions of Tenuipalpidae do not refer to the spermatheca. In Ochoa et al. 2011 suggested the possibility to use this structure in the taxonomy of Brevipalpus, and Beard et al. (2015) used the morphology of the spermatheca as a characteristic helping in separation of some species from the B. phoenicis complex. In fact, B. phoenicis sensu lato was divided into at least eight species (Beard et al. 2015) on the basis of morphological data, using shape of the spermatheca as one of the key characters. Validation of these characters by DNA analysis is still in progress.

Hence, in the present study morphological and ultrastructural details of the insemination system (including the spermatheca) are compared in females of five Brevipalpus species. These species represent different morphological groups and are studied using light (LM), transmission (TEM) and scanning electron microscopy (SEM). The aim is to verify, by means of SEM high magnification images, whether the morphological differences observed by LM are confirmed and whether variations in the shape of the spermatheca can be a species-specific character usable in discerning Brevipalpus species. 


\section{Materials and methods}

Females of the following species were investigated: Brevipalpus papayensis (Baker), B. obovatus, Brevipalpus yothersi (Baker), B. californicus and Brevipalpus tuberellus De Leon. All these species are considered reproduced parthenogenetically and, according to Baker and Tuttle (1987), B. yothersi and B. papayensis are representative of the morphological species group B. phoenicis; B.californicus of the B. californicus group; B. tuberellus of the B. cuneatus group; and B. obovatus of the B. obovatus group. These five species represent four morphological groups corresponding to molecular clades (Navia et al. 2013; Alves et al. 2019).

Brevipalpus papayensis was obtained from a single female collected from a coffee orchard in the State of São Paulo, Brazil ( $\left.22^{\circ} 52^{\prime} 00.7^{\prime \prime} \mathrm{S}, 47^{\circ} 04^{\prime} 53.2^{\prime \prime} \mathrm{W}\right)$, starting date 08/05/2018. Brevipalpus obovatus population was obtained from a single female collected from Solanum violifolium Schott in São Paulo state ( $\left.22^{\circ} 42^{\prime} 46.9^{\prime \prime} \mathrm{S}, 47^{\circ} 38^{\prime} 52.4^{\prime \prime} \mathrm{W}\right)$, starting date 03/02/2018. Brevipalpus yothersi population was obtained from a single female collected from Citrus sinensis L. in São Paulo state $\left(22^{\circ} 42^{\prime} 33.4^{\prime \prime} \mathrm{S}, 47^{\circ} 38^{\prime} 05.5^{\prime \prime}\right.$ W), starting date 15/08/2016.

Rearings of these three species were performed at the ESALQ (Luiz de Queiroz College of Agriculture) Piracicaba (São Paolo, Brazil) and realized on picked off leaves of the specific host plants (coffee, citrus and $S$. violifolium) following a modification of the method described by Overmeer (1985). The leaves were used as rearing arenas with their margins delimited by wet cotton to prevent mites from running away. Leaves were put on top of a water-soaked sponge covered with filter paper (Fig. 1a). This procedure allowed the leaves to last for about 1 month. The rearings were kept in a climatized room at $26 \pm 2{ }^{\circ} \mathrm{C}$, $65 \pm 10 \%$ relative humidity and 14:10 h L:D photoperiod (Fig. 1b).
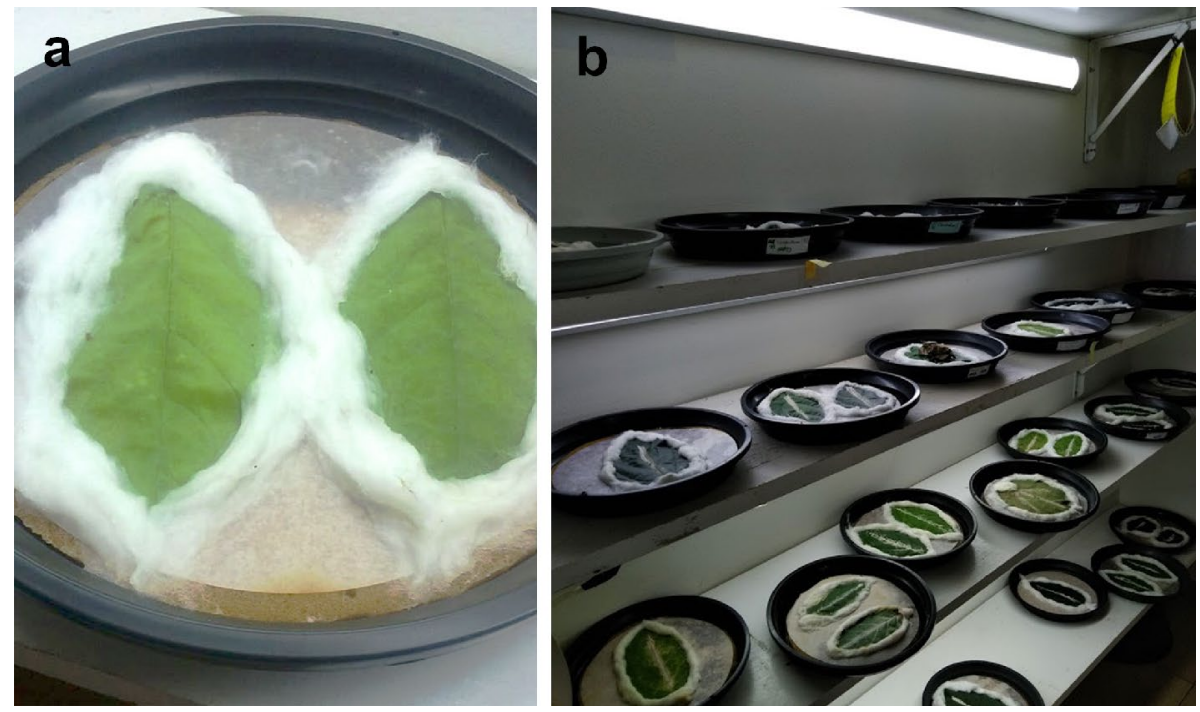

Fig. 1 Rearings of Brevipalpus species. a Picked leaves used as rearing arenas. Their margins are delimited by wet cotton to prevent mites from running away. Leaves lie on the top of a water-soaked sponge covered with filter paper. b Rearings in a climatized room 
Females of $B$. californicus were collected from Oncidium sp. in São Paulo state $\left(22^{\circ}\right.$ $42^{\prime} 33.7^{\prime \prime} \mathrm{S}, 47^{\circ} 38^{\prime} 08.7^{\prime \prime} \mathrm{W}$ ), date 13/09/2018 and stored in $100 \%$ ethanol until their use. Females of B. tuberellus were collected from Nectandra megapotamica (Spreng.), in São Paulo state $\left(22^{\circ} 42^{\prime} 33.3^{\prime \prime} \mathrm{S}, 47^{\circ} 38^{\prime} 07.3 \mathrm{~W}\right)$, date $25 / 09 / 2019$, and processed for this study.

\section{Light microscopy (LM)}

Specimens $(n=25)$ of all listed species were mounted in Hoyer's medium (Walter and Krantz 2009) for LM. Observations and micrographs were performed with a Zeiss Axioimager II light microscope provided with DIC and Zeiss digital camera.

\section{Transmission electron microscopy (TEM)}

Specimens of B. papayensis, B. yothersi and B. tuberellus $(\mathrm{n}=25)$ were processed for TEM. Females of these species were dissected and prefixed in ice-cold Karnovsky's (1965) for $3 \mathrm{~h}$. After prefixation, specimens were rinsed in buffer solution (cacodylate buffer $\mathrm{pH}$ 7.3) for $2 \mathrm{~h}$, subsequently post-fixed in $2 \%$ buffered $\mathrm{OsO} 4(1.5 \mathrm{~h})$, rinsed again in buffer solution ( $2 \mathrm{~h}$ ), dehydrated with graded ethanol up to $100 \%$ ethanol, embedded in Spurr's mixture (Spurr 1969) and finally polymerized for $48 \mathrm{~h}$ at $65{ }^{\circ} \mathrm{C}$. Ultrathin serial sections were cut with a Leica EM UC6 ultramicrotome using a diamond knife (Diatome). The sections, collected with copper grids covered with a formvar film, were double-stained with uranyl acetate and lead citrate according to Reynolds et al. (1963) and studied with a JEOL JEM-1011 TEM, images being recorded digitally.

\section{Scanning electron microscopy (SEM)}

To obtain three-dimensional pictures in high magnification of the insemination system, a methodology already applied for the same purpose to other groups of mites was used (Di Palma and Alberti 2001; Alberti et al. 2009).

Some specimens $(n=45)$ of all listed species were immersed in lactic acid for around 2 weeks at $50{ }^{\circ} \mathrm{C}$ to dissolve the soft tissues present in the mite body while preserving the cuticle-lined structures. When the mites were completely clarified (translucent) they were dehydrated in graded ethanol and critical point dried in a Leica EM CPD300 critical point dryer. Then the specimens were placed on Al stubs using double sticking carbonated tapes and, using a fine needle, the dorsal shields were removed to expose the insemination system. Then the specimens were sputter-coated with gold in a Baltec SCD050 sputter coater and studied with a JEOL IT300 SEM. Images were registered digitally.

\section{Results}

The insemination system in Brevipalpus, as reported by Pijnacker et al. (1981), Alberti and Coons (1999) and Alberti et al. (2014a), is composed of the insemination duct and the seminal receptacle (spermatheca or vesicle) (Fig. 2a), where the sperm is supposed to be stored.

In all species studied with TEM the long insemination duct begins at the copulatory pore (Fig. 2b, c) ventrally located of the anal canal (Fig. 2c) and dorsally of the vagina 

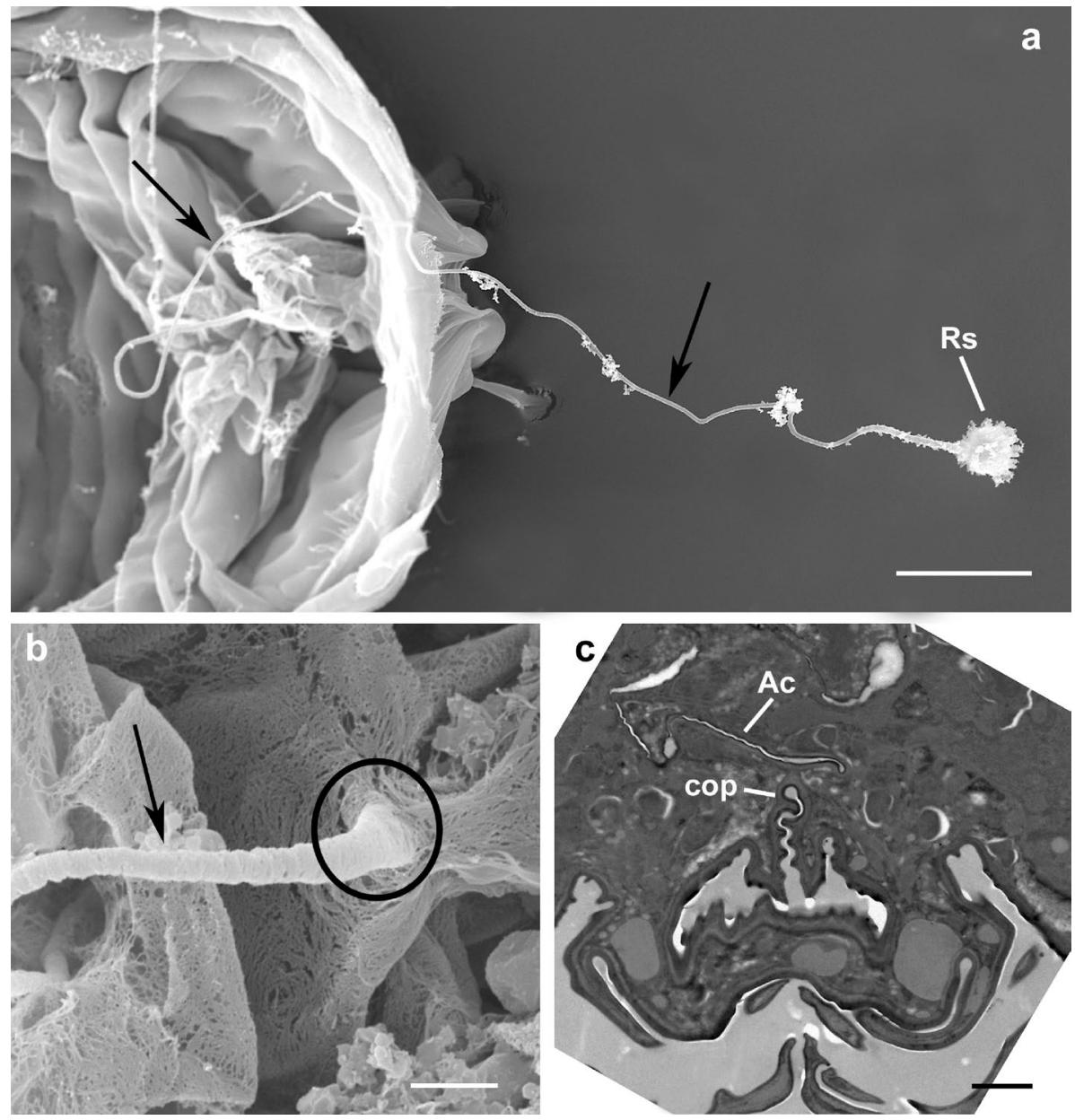

Fig. 2 Brevipalpus papayensis: insemination system. a SEM: overview of insemination system composed of a long insemination duct (arrows) and seminal receptacle (spermatheca, or vesicle); b SEM: detail of insemination duct (arrow) close to insemination pore (circle) (view from inside of mite body with dorsal shield removed); c TEM: cross section showing copulatory pore ventral to the anal canal. Abbreviations: Ac, anal canal; cop, copulatory pore; Rs, seminal receptacle. Scale bar: a $10 \mu \mathrm{m}$; b $1 \mu \mathrm{m}$; c $2 \mu \mathrm{m}$

(Fig. 3a). In cross section, the duct appears round and shows a rather thick cuticle (Fig. 3b) that in the anterior portion of the duct appears bi-layered with an inner (towards the lumen) layer more electron lucent and an external layer (towards the epithelium) more electron dense (Fig. 3b). The insemination duct, so called since it is supposed to be used by the male to introduce the penis (Alberti et al. 2014b) and fertilize the female, runs forward and performs some bending, or undulating, such that it is viewed more than once in some cross sections (Fig. 3c). It is quite difficult to follow, in cross sections, the path of the duct leading to the seminal receptacle due to the very small size of the duct diameter (ca. $0.3 \mu \mathrm{m}$; Figs. 3 and 4) and the unpredictable position of the duct in the body. In fact, the duct is pushed aside by the large oviduct, the growing oocytes and the digestive system, so that it can be located dorsally, laterally or ventrally (Fig. 4). Sometimes, a granular material is 

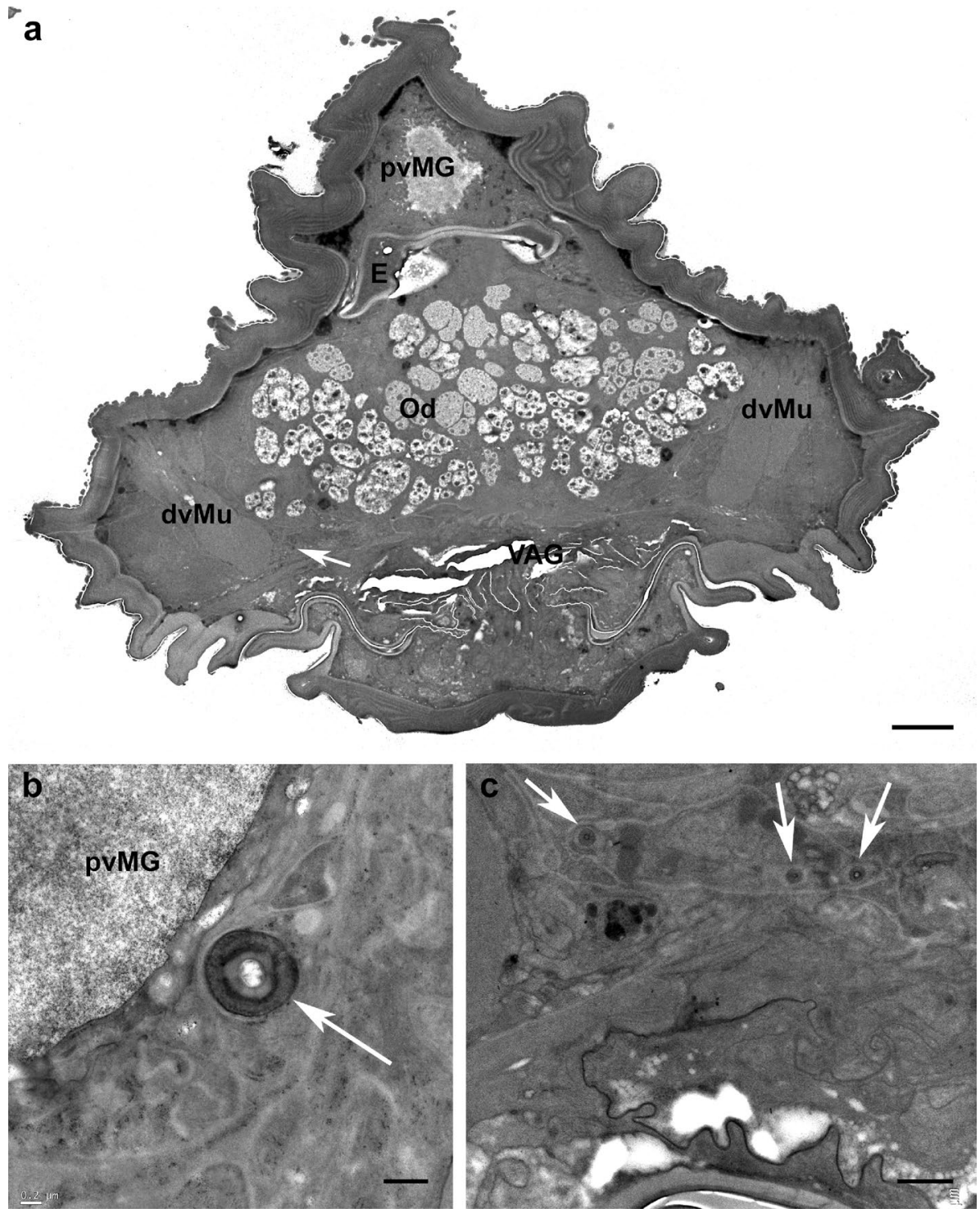

Fig. 3 TEM cross sections showing insemination duct (arrow) in different position in Brevipalpus tuberellus mite body. a Cross section at level of large oviduct showing position of insemination duct (arrow) ventral of oviduct and dorsal of vagina; b B. papayensis: cross section of insemination duct (arrow) close to postventricular midgut; c $B$. tuberellus: cross section showing insemination duct cut several times (arrows). $d v M u$ dorsoventral muscles, $E$ egg, $O d$ oviduct, $p v M G$ postventricular midgut, $V A G$ vagina. Scale bar: a $5 \mu \mathrm{m} ; \mathbf{b}, \mathbf{c} 0.5 \mu \mathrm{m}$

visible inside the insemination duct lumen (Fig. 5a). As reported by Alberti et al. (2014a), the duct is surrounded by an epithelium that becomes enlarged while approaching the oviduct and the ovary (Fig. 5b-d). The cytoplasm of this tissue enveloping the duct contains microtubules, few mitochondria, ribosomes, lysosomes, dense aggregates of dark droplets, 


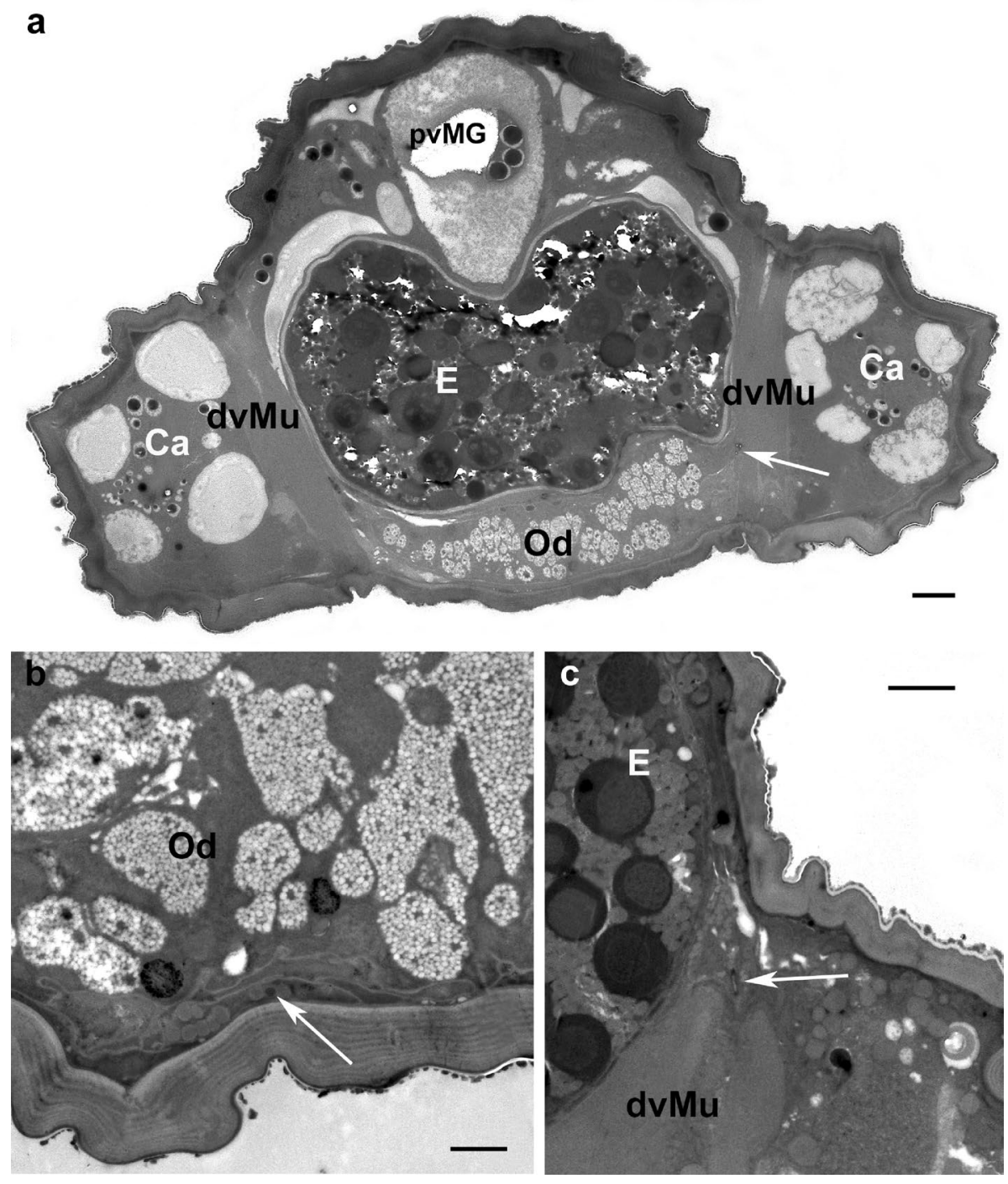

Fig. 4 Brevipalpus tuberellus TEM cross sections showing insemination duct (arrows) in different positions in mite body: a ventrolateral to egg; $\mathbf{b}$ ventral to oviduct; $\mathbf{c}$ in dorsal region of body, lateral to egg. $\mathrm{Ca}$ caecum, $d v M u$ dorsoventral muscles, $E$ egg, $O d$ oviduct, $p v M G$ postventricular midgut. Scale bar: a, c $5 \mu \mathrm{m}$; b $1 \mu \mathrm{m}$

likely of Golgi's origin, lipid inclusions (Fig. 5b-d), and rough endoplasmic reticulum with enlarged vesicles (Fig. 5e).

Close to its end, the insemination duct widens slightly (Figs. 5d and 6a, b) and terminates in the seminal receptacle (also called spermatheca) and still cuticle-lined (Fig. 6a, b). At this level, the epithelium embedding the duct and the spermatheca appears much thicker and achieves a rather complex arrangement of the cells showing heterogeneous inclusions (Figs. 5d and 6b). 

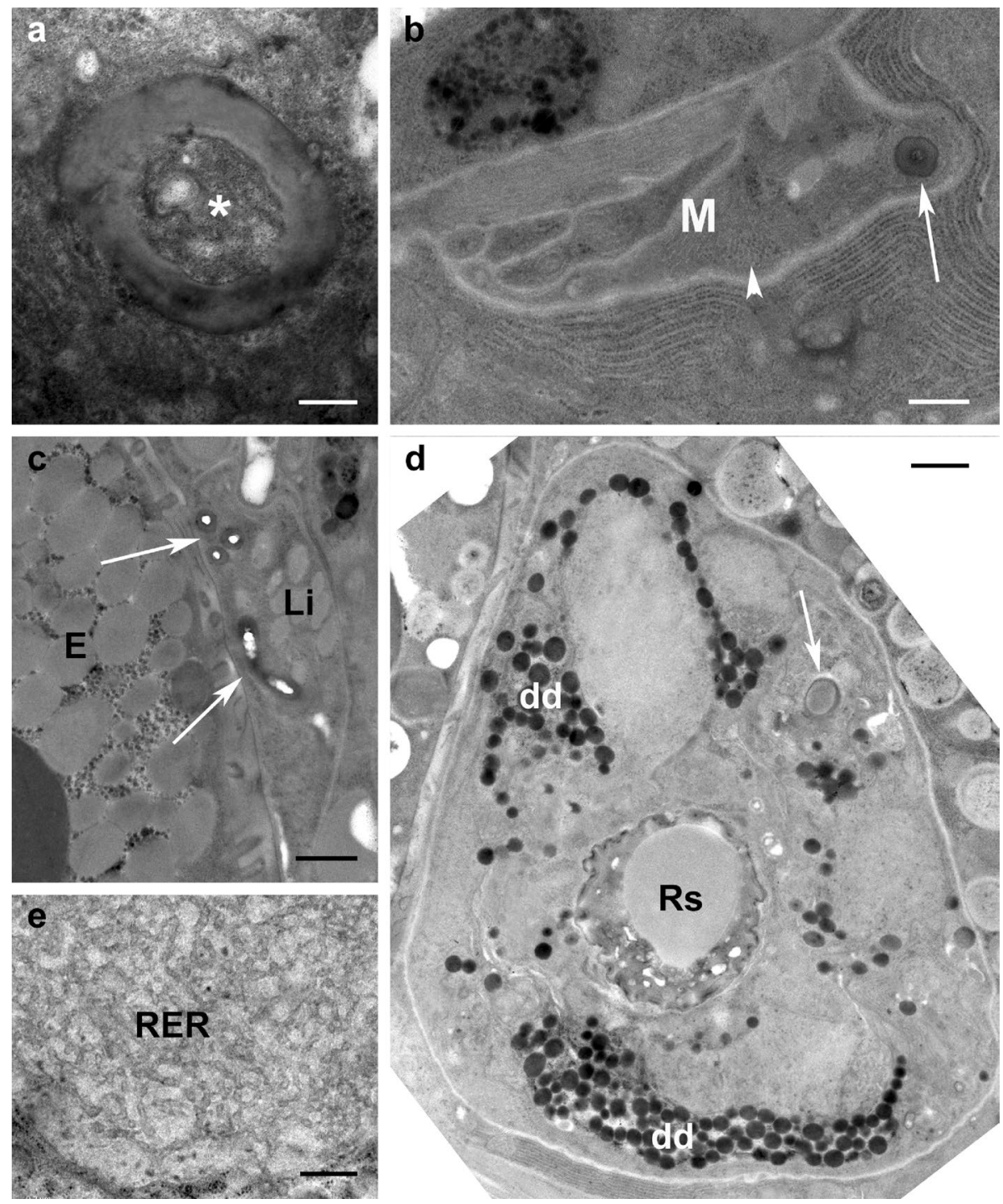

Fig. 5 TEM cross sections of insemination duct. a Brevipalpus yothersi: granular material (asterisk) sometimes visible inside insemination duct lumen; b-e B. tuberellus insemination duct (arrow) embedded in epithelium whose cytoplasm contains microtubules (arrowhead), few mitochondria, ribosomes, lysosomes, dense aggregates of dark droplets, lipid inclusions and enlarged rough endoplasmic reticulum. $d d$ dark droplets, $E$ egg, $L i$ lipid inclusion, $M$ mitochondrion, $R E R$ rough endoplasmic reticulum, $R s$, eminal receptacle. Scale bar: a $200 \mathrm{~nm} ; \mathbf{b} 0.4 \mu \mathrm{m}, \mathbf{c}, \mathbf{d} 1 \mu \mathrm{m} ; \mathbf{e} 0.5 \mu \mathrm{m}$

In cross sections, the seminal receptacle presents a well visible lumen surrounded by a cuticlar layer that is continuous with the duct cuticle. The thickness and the appearance of the receptacle walls look different in different species. In B. papayensis the rather thick and homogeneous cuticular layer forms an irregular external outline projecting in finger-like structures whose lumens connect to the lumen of the receptacle (Fig. 6c). Such finger-like 

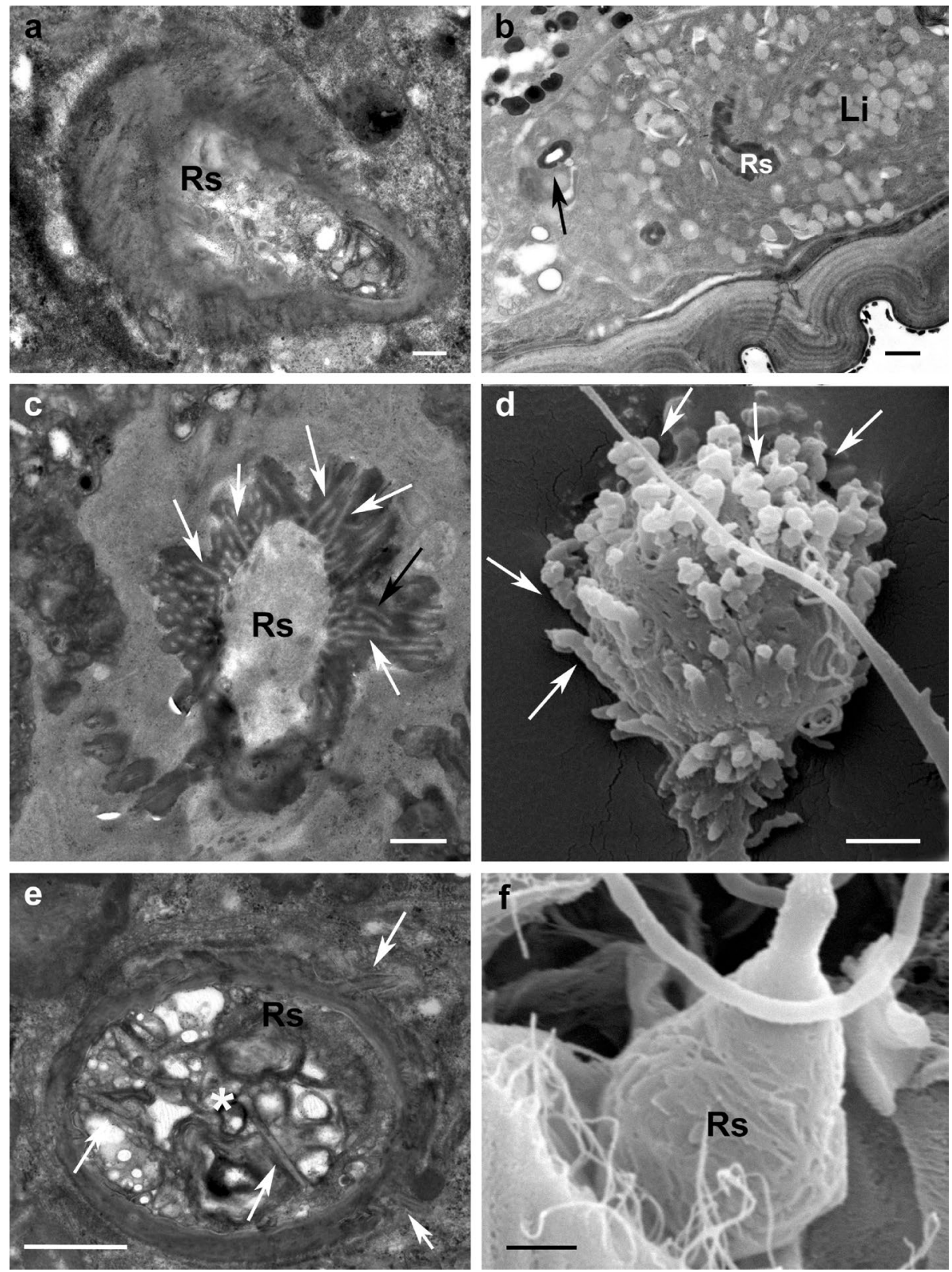

Fig. 6 Seminal receptacle. a Brevipalpus yothersi TEM cross section of insemination duct (arrow) widening to create a seminal receptacle still cuticle-lined; $\mathbf{b}$ B. tuberellus TEM cross section: insemination duct (arrow) and seminal receptacle embedded in thick epithelial tissue showing heterogeneous inclusions; $\mathbf{c} B$. papayensis TEM cross section: seminal receptacle with a central lumen delimited by a rather thick cuticular layer provided with finger-like structures. Each finger-like structure presents a central thin lumen (arrows) that communicates with lumen of receptacle; d SEM, B. papayensis seminal receptacle showing evident finger-like projections (arrows); e $B$. yothersi TEM cross section of seminal receptacle showing smooth external and internal cuticular layers except for few thin filaments (arrows) projecting into the vesicle lumen and outside the vesicle itself; moreover, some granular and unstructured material is visible inside lumen (asterisk); f SEM, B. tuberellus seminal receptacle showing external surface slightly irregular. Li lipid inclusion, $R s$ seminal receptacle. Scale bar: a $0.2 \mu \mathrm{m} ; \mathbf{b}, \mathbf{c} 0.5 \mu \mathrm{m} ; \mathbf{d}-\mathbf{f} 1 \mu \mathrm{m}$ 
projections are visible in SEM images as well (Fig. 6d). In B. yothersi the cuticlar layer is thinner with a smooth external and internal surface except for few thin filaments projecting both outside and into the lumen of the vesicle where some granular and unstructured material is visible (Fig. 6e). In B. tuberellus the external outline of the receptacle is slightly irregular whereas the internal surface is smooth (Figs. 5d and 6c). The irregular external surface of the receptacle is visible in SEM images as well (Fig. 6f).

Remarkably, in some Brevipalpus populations, undeveloped seminal receptacles have been observed by LM (A.D. Tassi, unpubl.). Moreover, in the present study a few females of the $B$. tuberellus and $B$. papayensis populations were detected not showing a seminal receptacle when examined under the light microscope. Among the studied females of $B$. papayensis, cross sections of one female (Fig. 7) showed the insemination duct ending in a very reduced receptacle (spermatheca) appearing like a small ball of cuticle without any lumen (Fig. 7c). Nevertheless, the peculiar tissue described as enveloping the insemination duct and the receptacle is still present (Fig. 7a, b).

Recently, Beard et al. (2012) reported the possibility, based on LM observations, that the shape of the seminal receptacles differs between species and even within populations of the same species and within such populations. Thus, beside ultrastructural observations of the insemination system with TEM, SEM investigations were performed to study the external morphology of the seminal receptacle (e.g., size and shape) and to compare these observations with the images obtained by LM. All studied species proved to have species-specific shapes of the spermatheca. In B. papayensis the roundish spermatheca is ca. 3-4 $\mu \mathrm{m}$ in size and shows numerous finger-like convoluted projections (Figs. 2a and 6d) that are clearly visible in SEM but discernible in lower magnification with light microscopy as well (Fig. 8a); in B. californicus, the vesicle is roundish (ca. $4 \mu \mathrm{m}$ ) but with finger-like extensions concentrated on the distal pole of the spermatheca (the one facing anteriorly) (Figs. 8b and 9a). In B. obovatus, the spermatheca is similar to B. papayensis (ca. $3.5 \mu \mathrm{m}$ ) and with longer and more divergent finger-like projections surrounding the external surface (Figs. 8c and 9b). In B. yothersi, the small spermatheca (ca. $2 \mu \mathrm{m}$ ) looks completely different, as it is oval with a smooth surface and a long tapering apical structure (Figs. 8d, e and 9c). Finally, B. tuberellus presents an oval spermatheca (ca. $3.5 \mu \mathrm{m}$ ) with an irregular external surface devoid of any projections (Figs. 6f and 9d).

\section{Discussion}

Five species of Brevipalpus, all considered reproduced parthenogenetically, have been studied regarding the ultrastructure of the female insemination system. Remarkably, the ultrastructure of the system proved to be similar to that described by Alberti et al. (2014b) in $B$. chilensis where the males are considered to be functional and thus the population should be reproduced sexually. In fact, even though in the studied species the insemination ducts leading to the receptacles (spermatheca) are very thin, their sizes are comparable to that observed in B. chilensis (ca. $0.3 \mu \mathrm{m}$ ); moreover, all receptacles of the studied species are hollow structures with a lumen as in B. chilensis (Figs. 5d and 6a, c and e). Thus, it seems that although parthenogenetic, these species have retained the general morphology of the insemination system without significant differences between parthenogenetic and bisexual species. The same phenomenon was observed in mesostigmatic mites of the genus Veigaia (Veigaiidae) (Alberti et al. 2009; Di Palma et al. 2012). Veigaiids are peculiar in terms of their reproduction in that males of many species are rarely or never found; yet, the 

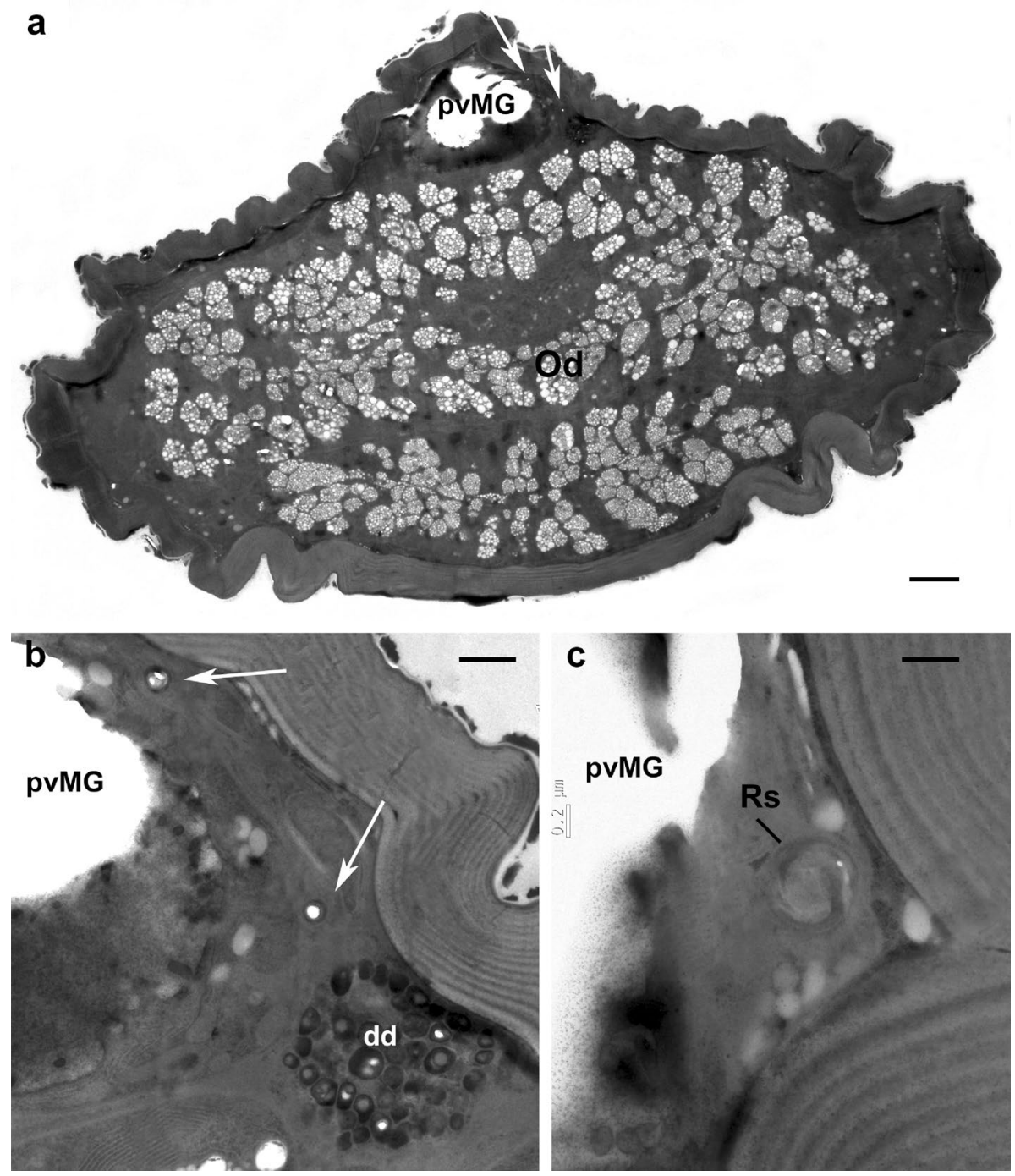

Fig. 7 Brevipalpus papayensis TEM. a Cross section at level of large oviduct showing insemination duct (arrow) cut twice and located dorsal in body on right side of postventricular midgut; $\mathbf{b}$ detail of previous image, showing duct cut twice and embedded in epithelial tissue with dark droplets; $\mathbf{c}$ another cross section of same specimen, showing insemination duct ending in a very reduced receptacle (spermatheca) appearing like a small ball of cuticle without any lumen. $d d$ dark droplets, $O d$ oviduct, $p v M G$ postventricular midgut, $R s$ seminal receptacle. Scale bar: a $5 \mu \mathrm{m}$; b $1 \mu \mathrm{m}$; c $0.5 \mu \mathrm{m}$

organization of the female reproductive system does not show relevant differences depending on whether being parthenogenetic or bisexual. In fact, in both cases the insemination system and the region involved in egg development and oviposition are similarly organized.

On this basis, and as Ochoa et al. (2011) and Beard et al. (2015) suggested the possibility of using the morphology of the spermatheca as a characteristic to separate species among the genus Brevipalpus, the receptacle structure of five species of Brevipalpus was 

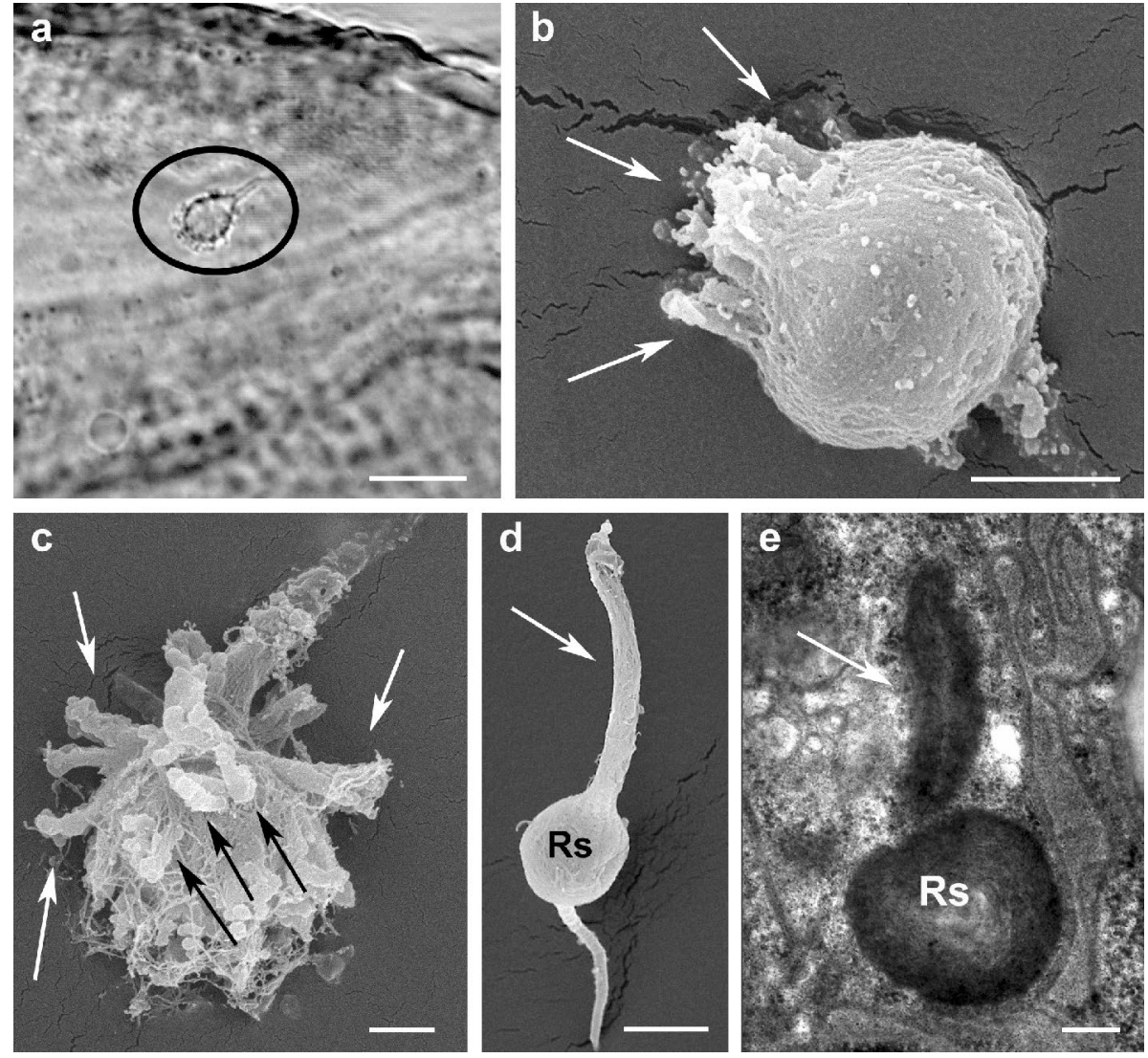

Fig. 8 Seminal receptacle. a LM Brevipalpus papayensis seminal receptacle (circle) with finger-like projections described in TEM and SEM (compare with Fig. 6c, d); b B. californicus SEM of roundish vesicle with finger-like extensions (arrows) concentrated on distal pole of spermatheca (facing anteriorly); $\mathbf{c} B$. obovatus SEM of spermatheca similar to B. papayensis but with longer, more divergent finger-like projections (arrows); d, e $B$. yothersi SEM d of spermatheca, oval with long tapering apical structure (arrow) visible in TEM section as well (e, arrow). Rs seminal receptacle. Scale bar: a $10 \mu \mathrm{m} ; \mathbf{b}, \mathbf{d}, \mathbf{e} 2 \mu \mathrm{m} ; \mathbf{c} 1 \mu \mathrm{m}$

investigated by SEM to support the idea that its shape and/or size might be species-specific. In our observations the studied species proved to have a seminal receptacle with a peculiar shape distinctive for each species. As SEM images are three-dimensional and in high resolution, the differences hypothesized by LM studies are confirmed (Figs. 6, 8 and 9). Thus, morphological differences between seminal receptacles of different species are discernable to some extent even with a regularly equipped compound microscope (Figs. 8a and 9). However, a limiting aspect is that for several described Brevipalpus species, authors were not able to detect the spermatheca by means of light microscopy, ascribing this to the clearing action of the mounting medium and the young age of the females (Baker and Tuttle 1987). Of course, it is crucial to ascertain whether the seminal receptacle was not detected because of its clarification or reduced sclerotization related to the young age of the females, or because there are some species or populations among the same species that have an undeveloped spermatheca. Cross sections of one female of B. papayensis showed an insemination duct ending with a tiny ball of cuticle (ca. $0.6 \mu \mathrm{m}$ in cross section; Fig. $7 \mathrm{c}$ ) 

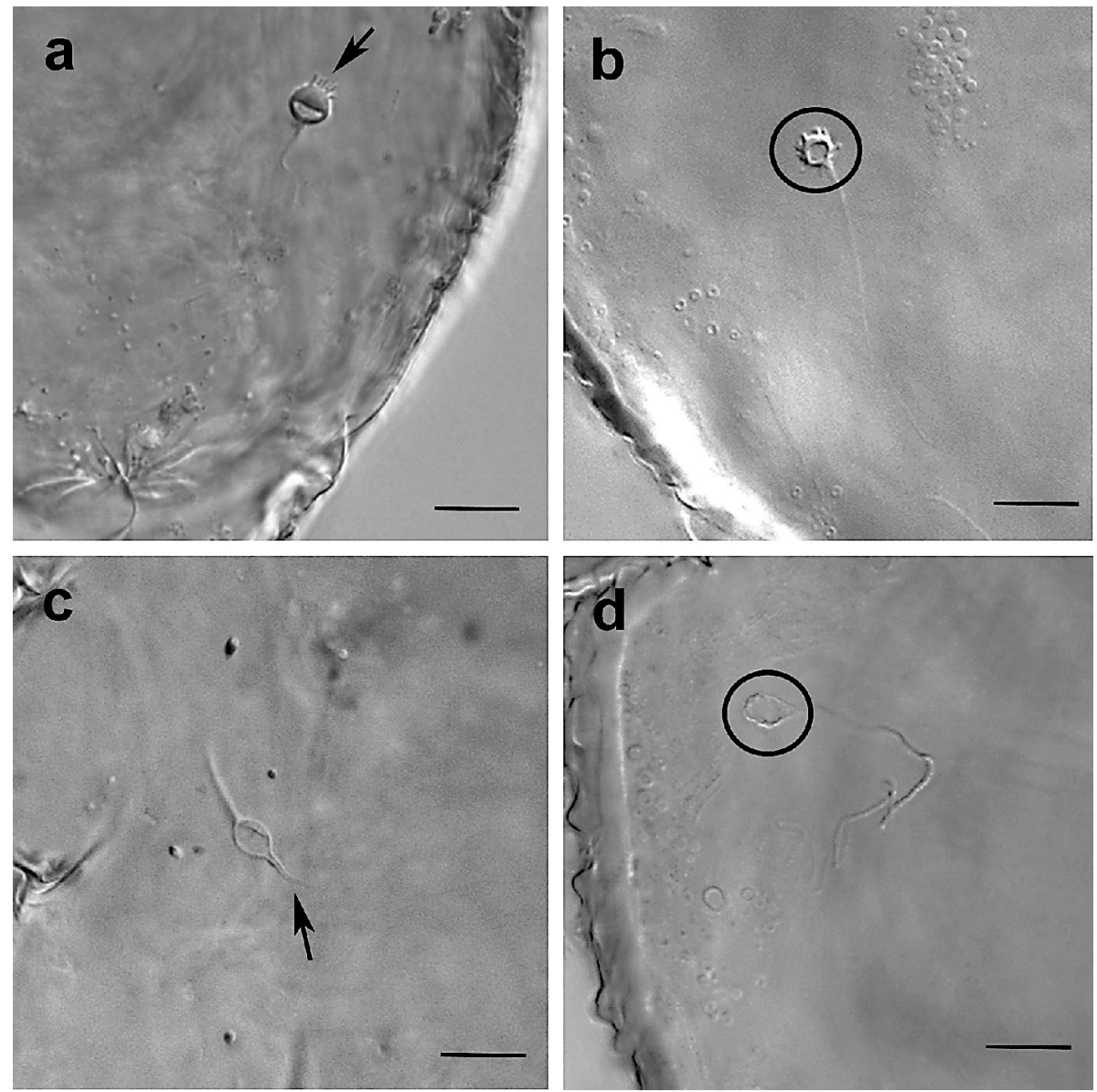

Fig. 9 Seminal receptacle (spermatheca) of the studied species in LM. a Brevipalpus californicus, the vesicle shows finger-like extensions concentrated on one pole (arrow). b B. obovatus, the spermatheca (circle) presents long, divergent finger-like projections surrounding the external surface. c $B$. yothersi, the spermatheca is oval with a smooth surface and a long tapering apical structure (arrow). d $B$. tuberellus presents an oval spermatheca (circle) with an irregular external surface devoid of any projections. Scale bar: $10 \mu \mathrm{m}$

devoid of any lumen and too small to be detected by LM. This female was collected and processed for TEM together with the others that proved to have a well-developed receptacle. Thus, it seems that among the same species and the same population there might be some specimens whose receptacle may be undeveloped and thus not possible to discern when the mite is slide-mounted.

It is now clear that the inability to detect the spermatheca in some specimens by LM cannot be ascribed to the clarification of the mounting medium or to a reduced sclerotization of this structure related to the young age of the females. Instead, it seems that there are some specimens that have an undeveloped receptacle (Fig. 7c). On the other hand, Alberti et al. (2014a) supposed that differences in LM figures of the shape of the receptacle between populations of the same species and even within such populations may also be due to differences in the state of insemination and structure development. One could hypothesize that differences in physiological condition or age of the females present in the same 
population or in different populations of the same species can result in various degrees of development of the seminal receptacle (spermatheca) of the insemination system (compare Figs. 6c and 7c, each a cross section of the receptacle of one of two B. papayensis specimens). Nevertheless, it is still uncertain how the development of the spermatheca can be modified during the female's life span. In this respect, in Phytoseiidae (Di Palma and Alberti 2001) and Veigaiidae (Alberti et al. 2009; Di Palma et al. 2012) an epithelium enveloping the vesicle of the sperm access system has been described. Moreover, Di Palma and Alberti (2001) reported that the epithelium appearance varies and that, in some regions, extensive dark inclusions, together with endoplasmic reticulum, free ribosomes, and mitochondria were visible, and that the vesicle wall as well could have different appearances likely depending on the mating state. Also in Brevipalpus species, an epithelial tissue is present enveloping the insemination duct and the seminal receptacle (Figs. 5b-e, 6b and $7 \mathrm{~b}$ ). Such epithelium, containing microtubules, mitochondria, ribosomes, lysosomes, dense dark droplets and lipid inclusions, is involved in the secretion of the cuticle wall of the receptacle and thus, likely, in its development and in formation of a normal receptacle or a reduced one. Of course, this hypothesis needs to be tested by LM observations of a high number of females belonging to one species and collected from a single population to support the idea that the development of the spermatheca can be variable, even within the same population, according to different physiological states of the specimens. Moreover, it would be interesting to evaluate the percentage of females showing or not showing welldeveloped spermathecae within a population and whether such percentages can vary during the seasons or according to some environmental parameters.

Thus, according to the present observations, it seems that the seminal receptacle has specific morphological features that can be useful for taxonomic purposes, yet its appearance within a population might be variable in a way that needs to be ascertained. This is definitely another important step towards successful use of seminal receptacle morphology in the diagnosis of the large genus Brevipalpus, as well as of Brevipalpus species groups; it may even have diagnostic potential in other genera of the large family Tenuipalpidae.

Acknowledgements Open access funding provided by Università di Foggia within the CRUI-CARE Agreement. The authors would like to thank Dr. E.E. Lindquist, Science \& Technology Branch, Agriculture \& Agri-Food Canada, Ottawa, Canada, who provided constructive comments on this manuscript, and the anonymous reviewers whose comments helped to improve the paper.

Author contributions Conceptualization: EWK, ADP. Funding acquisition: EW Kitajima. Species identification and mite rearing: ADT. Material preparation, data collection and analysis: ADP. First draft of manuscript written by ADP, with all authors commenting on subsequent versions of the manuscript. All authors read and approved the final manuscript.

Funding This study was supported by the Fundação de Amparo à Pesquisa do Estado de São Paulo (FAPESP): Antonella Di Palma, visiting researcher of Fapesp- 2018/13241-0, Fapesp thematic project on Brevipalpus-transmitted viruses (of E.W. Kitajima)- Fapesp 2014/08458-9, Post-doctoral fellowship for Aline D. Tassi Fapesp 2018/12252-8

\section{Compliance with ethical standards}

Conflict of interest The authors declare that they have no conflict of interest.

Open Access This article is licensed under a Creative Commons Attribution 4.0 International License, which permits use, sharing, adaptation, distribution and reproduction in any medium or format, as long as you give appropriate credit to the original author(s) and the source, provide a link to the Creative Commons licence, and indicate if changes were made. The images or other third party material in this article are included in the article's Creative Commons licence, unless indicated otherwise in a credit line to the 
material. If material is not included in the article's Creative Commons licence and your intended use is not permitted by statutory regulation or exceeds the permitted use, you will need to obtain permission directly from the copyright holder. To view a copy of this licence, visit http://creativecommons.org/licenses/by/4.0/.

\section{References}

Alberti G, Coons LB (1999) Acari - mites. Microscopic anatomy of invertebrates. Wiley, New York

Alberti G, Di Palma A, Krantz GW, Błaszak C (2009) First ultrastructural observations on a putative sperm access system in veigaiid females (Veigaiidae, Gamasida). In: Sabelis MW, Bruin J (eds.) Trends in Acarology - Proceedings 12th International Congress of Acarology. Springer, Dordrecht, pp. 59-64

Alberti G, Tassi AD, Kitajima EW (2014a) Anatomy and fine structure of Brevipalpus mites (Tenuiplapidae) - economically important plant-virus vectors - part 6: female reproductive system. Zoologica $160: 145-172$

Alberti G, Tassi AD, Kitajima EW (2014b) Anatomy and fine structure of Brevipalpus mites (Tenuiplapidae) - economically important plant-virus vectors - part 5: male reproductive system. Zoologica 160:113-144

Alves JLS, Ferragut F, Mendonça RS, Tassi AD, Navia D (2019) A new species of Brevipalpus (Acari: Tenuipalpidae) from the Azores Islands, with remarks on the B. cuneatus species group. Syst Appl Acarol 24(11):2184-2208

Baker EW, Tuttle DM (1987) The false spider mites of Mexico (Tenuipalpidae: Acari). U S Dep Agric Agric Res Serv Tech Bull 1706:1-236

Beard JJ, Ochoa R, Bauchan GR, Trice MD, Redford AJ, Walters TW, Mitter C (2012) Flat mites of the World - Part I. Raioiella and Brevipalpus - Identification Technology Program. http://idtools.org/id/ mites/flatmites/. Accessed 15 July 2020

Beard JJ, Ochoa R, Braswell EW, Bauchan GR (2015) Brevipalpus phoenicis (Geijskes) species complex (Acari: Tenuipalpidae): a closer look. Zootaxa 3944:1-68

Castagnoli M (1974) La spermateca in alcune specie di Brevipalpini (Acarina, Tenuipalpidae). Redia 55(1):85-88

Castro EB, Mesa NC, Feres RJF, Moraes GJ, Ochoa R, Beard JJ, Demite PR (2019) Tenuipalpidae database. http://www.tenuipalpidae.ibilce.unesp.br Accessed May 2020

Chant DA, McMurtry JA (2007) Illustrated keys and diagnoses for the genera and subgenera of the phytoseiidae of the world (Acari: Mesostigmata). Indira Publishing House, West Bloomfield

Chetverikov P, Petanović RU (2016) Longest endoparasitic eriophyoid mite (Acari, Eriophyoidea): description of Novophytoptus longissimus n. sp. and remarks on size limits in eriophyoids. Syst Appl Acarol 21(10): 1547

Chetverikov PE, Cvrković T, Makunin A, Sukhareva S, Vidović B, Petanović R (2015) Basal divergence of Eriophyoidea (Acariformes, Eupodina) inferred from combined partial COI and $28 \mathrm{~S}$ gene sequences and CLSM genital anatomy. Exp Appl Acarol. https://doi.org/10.1007/s10493-015-9945-9

Chetverikov PE, Cvrković T, Efimov PG, Klimov PB, Petanović RU, Romanovich AE, Schubert MA, Sukhareva SI, Zukoff SN, Amrine J (2020) Molecular phylogenetic analyses reveal a deep dichotomy in the conifer-inhabiting genus Trisetacus (Eriophyoidea: Nalepellidae), with the two lineages differing in their female genital morphology and host associations. Exp Appl Acarol 81:287-316

Childers CC, French JV, Rodrigues JCV (2003) Brevipalpus californicus, B. obovatus, B. phoenicis and B. lewisi (Acari: Tenuipalpidae): a review of their biology feeding injury and economic importance. Exp Appl Acarol 30(1):5-28

Di Palma A, Alberti G (2001) Fine structure of the female genital system in phytoseiid mites with remarks on egg nutrimentary development, sperm-access system, sperm transfer, and capacitation (Acari, Gamasida, Phytoseiidae). Exp Appl Acarol 25:525-591

Di Palma A, Alberti G, Błaszak C, Krantz GW (2012) Morphological and functional adaptations of the female reproductive system in Veigaiidae (Acari: Gamasida) and implications regarding the systematic position of the family. Zool Anz 251(2012):49-70

Donnadieu AL (1875) Recherchers pour servir a l'histoire des Tétranyques. Thèses. Faculté des Sciences de Lyon, Francia

Groot TVM, Breeuwer JAJ (2006) Cardinium symbionts induce haploid thelytoky in most clones of three closely related Brevipalpus species. Exp Appl Acarol 39(3/4):257-271

Karnovsky MJ (1965) A formaldehyde-glutaraldehyde fixative of high osmolarity for use in electron microscopy. J Cell Biol 27:137-138 
Kitajima EW, Novelli VM, Alberti G (2014) Anatomy and fine structure of Brevipalpus mites (Tenuipalpidae) - Economically important plant-virus vectors. Part I. An update on the biology and economical importance of Brevipalpus mites. Zoologica 160:1-10

Mesa NC, Ochoa R, Welbourn WC, Evans GA, Moraes GJ (2009) A catalog of the Tenuipalpidae (Acari) of the world with a key to genera. Zootaxa 2098(1):1-185

Navia D, Mendonça RS, Ferragut F, Miranda LC, Trincado RC, Michaux J, Navajas M (2013) Cryptic diversity in Brevipalpus mites (Tenuipalpidae). Zool Scr 42(1):406-426

Ochoa R, Mineiro JLC, Martioli AL, Beard JJ, De Moraes GJ, Bauchan G, Sato ME (2011) Brevipalpus phoenicis In Brazil. Who is it? In: SIBAC - Simpósio Brasileiro de Acarologia, 3. Campinas. Resumos. CD-ROM

Overmeer WPJ (1985) Rearing and handling. In: Helle W, Sabelis MW (eds) Spider Mites: their biology, natural enemies and control, 1B edn. Elsevier, Amsterdam

Pijnacker LP, Ferwerda MA, Helle W (1981) Cytological investigations on the female and male reproductive system of the parthenogenetic privet mite Brevipalpus obovatus Donnadieu (Phytoptipalpidae, Acari). Acarologia 22(2):157-163

Reynolds ES (1963) The use of lead citrate at high $\mathrm{pH}$ as electron opaque stain in electron microscopy. J Cell Biol 17:208-212

Rodrigues JCV, Gallo-Meagher M, Ochoa R, Childers CC, Adams BJ (2004) Mitochondrial DNA and RAPD polymorphism in the haploid mite Brevipalpus phoenicis (Acari: Tenuipalpidae). Exp Appl Acarol 34:275-290

Spurr AR (1969) A low-viscosity epoxy resin embedding medium for electron microscopy. J Ultrastruct Res 26:31-43

Vacante V (1983) Prima raccolta di acari Tetranichidi in Sicilia. Phytophaga 1:41-132

Vacante V (1984) Note sul Briobiiniitaliani (Acari: Tetranychidae) I. Frustula. Entomologica 7(8):559-573

Walter DE, Krantz GW (2009) Collecting, rearing and preparing specimens. In: Krantz GW, Walter DE (eds) A manual of acarology, 3rd edn. Texas Tech University Press, Lubbock

Welbourn WC, Ochoa R, Kane EC, Erbe EF (2003) Morphological observations on Brevipalpus phoenicis (Acari: Tenuipalpidae) including comparisons with B. californicus and B. obovatus. Exp Appl Acarol 30:107-133

Publisher's Note Springer Nature remains neutral with regard to jurisdictional claims in published maps and institutional affiliations. 